\title{
CHANGE OVER TIME IN THE HUMAN IMMUNODEFICIENCY VIRUS RISK PERCEPTIONS OF YOUTH
}

\author{
${ }^{1}$ Ann M. Beutel and ${ }^{2}$ Kermyt G. Anderson \\ ${ }^{1}$ Department of Sociology, University of Oklahoma Norman, \\ 780 Van Vleet Oval, Rm. 331 Norman, OK 73019, USA \\ ${ }^{2}$ Department of Anthropology, University of Oklahoma, Norman, OK, USA
}

Received 2013-04-05, Revised 2013-04-29; Accepted 2013-04-29

\begin{abstract}
Although the vulnerability of young people to HIV/AIDS continues to be a serious concern in South Africa, no research has used a representative sample of South African youth to examine whether individual Human Immunodeficiency Virus (HIV) risk perceptions change over time and, if they do, what factors are associated with change. Using data from the Cape Area Panel Study, a multi-racial, longitudinal study of youth and their households, this study examined whether youth change their HIV risk perceptions over a four-year period and whether sexual behaviors, knowing someone with HIV, gender and race are associated with any change. Overall, changes in HIV risk perceptions tend to be small. As predicted, sexual activity is associated with increases in risk perceptions. Contrary to predictions, condom use at last sex is associated with increases in risk perceptions and knowing someone with HIV is associated with decreases in risk perceptions. In addition, there is variation by gender and by race in the factors associated with change in risk perceptions. This study serves as an initial examination of change in the HIV risk perceptions of South African youth; further investigation of their HIV risk perceptions over time is needed.
\end{abstract}

Keywords: HIV/AIDS, Risk Perceptions, First Sex

\section{INTRODUCTION}

In recent years, hopeful signs regarding the HIV/AIDS epidemic among young people in South Africa have emerged. Human Immunodeficiency Virus (HIV) prevalence among young people in South Africa appears to be stabilizing. For 15-24 year-olds, national HIV prevalence rates were estimated at $9.3 \%$ in $2002,10.3 \%$ in 2005 and $8.7 \%$ in 2008, the most recent year for which national HIV prevalence data are available (Shisana and Simbayi, 2002; Shisana et al., 2009). HIV incidence appears to have declined in recent years among teenage males and females and 20-24 year-old females (Fraser-Hurt et al., 2011), which has been attributed to increases in condom use among young people (Shisana et al., 2009).

In spite of these encouraging trends, the vulnerability of young people to HIV/AIDS continues to be a serious concern in South Africa. HIV transmission largely occurs through heterosexual intercourse in South Africa and portions of the youth population continue to engage in sexual behaviors that place them at risk of HIV infection (Shisana et al., 2009; Fraser-Hurt et al., 2011). Risk perceptions are a central component of many models of health behavior (for a recent review, Aiken et al., 2012). These models give rise to the behavior motivation hypothesis, or the prediction that individuals who perceive themselves to be at risk of a disease will engage in behaviors known to prevent the disease (Brewer et al., 2004). Numerous studies of disease have tested the behavior motivation hypothesis; fewer studies have tested the risk reappraisal hypothesis, or the prediction that taking an action believed to reduce risk of a disease will lower self-perceived risk for the disease (Brewer et al., 2004). Research to date (to the best of our knowledge) has not specifically considered whether the HIV risk perceptions of South African youth change over time and

Corresponding Author: Ann M. Beutel, Department of Sociology, University of Oklahoma Norman, 780 Van Vleet Oval, Rm. 331 Norman, OK 73019, USA Tel: 405-325-2784 Fax: 405-325-7825 
if they do, what factors are associated with change. This study uses data from the Cape Area Panel Study (CAPS), a longitudinal study of youth and their households from Cape Town, South Africa, to examine whether HIV risk perceptions change over a four-year period and whether sexual behaviors, knowing someone with HIV, race and gender are associated with any change.

\subsection{HIV Risk Perceptions}

A number of studies have found that young South Africans often perceive their risk of HIV infection to be low, even if they engage in sexual risk behaviors (Macintyre et al., 2004; Anderson et al., 2007; Kenyon et al., 2010a; Fraser-Hurt et al., 2011), which may reflect youthful optimism and feelings of invulnerability (Moore and Rosenthal, 1991; Macintyre et al., 2004). But studies have found that young South Africans have at least moderate levels of knowledge about the sexual transmission of HIV (Anderson and Beutel, 2007; Shisana et al., 2009; Fraser-Hurt et al., 2011), and in keeping with health behavior models, studies using longitudinal data have found that South African youth with higher levels of self-perceived risk have lower odds of subsequently engaging in some sexual risk behaviors, such as first sex (Anderson et al., 2007; Tenkorang et al., 2009; 2011). Little attention has been paid to whether HIV risk perceptions change over time in South Africa or other sub-Saharan African countries. Research on change in HIV risk perceptions mostly has investigated whether HIV risk perceptions are affected by exposure to HIV prevention interventions. This research has shown that some sex and education programs may be effective at increasing HIV risk perceptions (Kirby et al., 2007).

In addition to sexual risk behaviors, knowing someone with HIV may be important for HIV risk perceptions; experiential theory (Macintyre et al., 2004) suggests young people may have higher HIV risk perceptions at one point in time or may be more likely to increase their HIV risk perceptions over time if they know someone who has HIV. Little attention has been paid to these possibilities, although there is some evidence that knowing someone who died of AIDS is associated with higher HIV risk perceptions (Anderson et al., 2007; Kenyon et al., 2010a).

Gender and race may be important for HIV risk perceptions and change in them. Compared to their male counterparts, young South African females (ages 15 and older) are more likely to have HIV and to report engaging in some sexual risk behaviors (e.g., less frequent condom use) but are less likely to report engaging in other sexual risk behaviors (e.g., multiple sexual partners over a 12-month period) (Kincaid and Parker, 2008; Pettifor et al., 2009; Shisana et al., 2009; Fraser-Hurt et al., 2011). Cross-sectional research on young South Africans has found either higher HIV risk perceptions for females than for males or similar levels of HIV risk perceptions for both genders (Pettifor et al., 2004; Shisana et al., 2005; Anderson et al., 2007). Research also suggests that some sexual behaviors (e.g., time since sexual debut) may be associated with HIV risk perceptions at one point in time for females but not for males (Kenyon et al., 2010a).

HIV prevalence varies by race in South Africa, with much higher prevalence rates for blacks than for coloureds, whites and Indians (Kincaid and Parker, 2008; Fraser-Hurt et al., 2011). Multiple studies of South African youth have shown that engagement in some sexual risk behaviors (e.g., ever had sex and younger age at first sex) are more common among young blacks than others (Dinkelman et al., 2007; Tenkorang et al., 2009; Kenyon et al., 2010b; Fraser-Hurt et al., 2011), but there is evidence that blacks are more likely than coloureds to report condom use at last sex (Dinkelman et al., 2007). Research on HIV risk perceptions at one point in time has found higher levels of self-perceived risk for coloured and white males relative to black males and lower self-perceived risk for coloured females relative to black females, with no significant differences in selfperceived risk between white and black females (Anderson et al., 2007). In addition, cross-sectional research suggests sexual risk behaviors may be correlated with HIV risk perceptions for whites and coloureds but not for blacks (Kenyon et al., 2010a).

\subsection{Hypotheses}

Drawing upon the risk reappraisal hypothesis, we predict that engagement in sexual risk behaviors will be associated with increases in HIV risk perceptions and engagement in risk reduction behaviors will be associated with decreases in HIV risk perceptions. Specifically, we expect that youth who are sexually active will be more likely to increase their HIV risk perceptions than individuals who remain virgins. For those who have had sex, we predict that earlier age at first sex will be associated with increases in HIV risk perceptions and condom use will be associated with decreases in risk perceptions. Drawing upon experiential theory, we expect that individuals who know someone with HIV will be more likely to increase their HIV risk perceptions than those who do not know someone with HIV. Lacking strong theoretical or empirical guidelines, 
we make no specific predictions about change in HIV risk perceptions by gender or by race. But findings of gender and racial variation in the correlates of HIV risk perceptions at one point in time lead us to expect that the factors associated with change in HIV risk perceptions over time will vary by gender and by race.

\section{MATERIALS AND METHODS}

\subsection{Data}

We used data from the first (2002) and fourth (2006) waves of the Cape Area Panel Study (CAPS), a longitudinal study of youth and their households that is representative of metropolitan Cape Town (Lam et al., 2008). CAPS was a data collection project of the University of Cape Town and several universities in the United States and operated under the approval of human subject review boards at all participating universities. Written consent was obtained from all respondents and written parental consent was obtained for respondents under age 18 . Both authors of this study were involved in the initial design and implementation of the study.

CAPS used a two-stage probability sample of households that was drawn to be representative of metropolitan Cape Town. Blacks and whites were oversampled with the goal of obtaining roughly equal numbers of black, coloured and white youth (Lam et al., 2008). The survey randomly sampled households within Cape Town and then randomly selected up to three young people (ages 14-22 at wave 1) within the sampled households for participation. The first (2002) wave of CAPS contains data from 4,752 youth ages 14-21 (approximately $45 \%$ black, $40 \%$ coloured and $16 \%$ white). The fourth (2006) wave of CAPS contains data from 3,439 youth. The overall retention rate for youth in the fourth wave, relative to the first wave, was $72 \%$. Retention rates for youth varied by racial group, with higher rates among blacks and coloureds (approximately 74 and $80 \%$, respectively) than among whites (about 42\%) (Lam et al., 2008). The lower response and retention rates for whites compared to non-whites are typical for survey research in South Africa (Lam et al., 2008). For all racial groups, moving away from Cape Town was the primary reason for nonresponse in later waves of the study; the greater movement of white youth out of Cape Town compared to blacks and coloureds was the main reason for their lower retention rate (Lam et al., 2008).

\subsection{Measures}

A number of measures from the CAPS youth questionnaire were used to test our hypotheses. They included the following.

\subsection{Change in HIV Risk Perceptions}

Our dependent variable was created using responses to a question on both the first and fourth wave surveys that asked respondents to evaluate whether they have "no risk" (coded as 1), a "small risk" (coded as 2), a "moderate risk" (coded as 3) or a "great risk" (coded as 4) of "getting the AIDS virus." To measure change in risk perceptions, we subtracted the value of the wave 1 self-perceived risk from the value of the wave 4 selfperceived risk. This resulted in an ordinal variable ranging from -3 to +3 , with negative values indicating a decrease in risk perceptions, a value of 0 indicating no change in risk perceptions and positive values indicating an increase in risk perceptions.

\subsection{Sexual Experience}

A question appearing on both the wave 1 and wave 4 surveys asked young people to indicate with a "yes" or "no" response whether they had ever had sexual intercourse (defined as "full penetration"). We used these questions to create a set of dummy variables measuring whether a respondent: (a) was a virgin at both waves (the omitted category in the analysis); (b) experienced first sex between wave 1 and wave 4; or (c) was a non-virgin at both waves.

\subsection{Other Sexual Risk Behaviors}

For analysis limited to respondents who were sexually experienced by wave 4 , we included an item from the wave 4 survey that measured whether they had used a condom at last sex, with "no" coded as 0 and "yes" coded as 1 . We also included a variable for age at first sex, coded in years, using age at first sex reported at wave 1 for respondents who had sex before wave 1 and age at first sex reported at wave 4 for respondents who reported first sex between waves 1 and 4 . In preliminary analyses, we included other sexual risk behaviors in the models (e.g., used a condom at first sex, number of sexual partners in the past year). Because these variables were not significant, they were dropped from later analyses.

\subsection{Knew Someone with HIV}

Responses to a question appearing on both the wave 1 and wave 4 surveys that asked respondents whether 
they knew someone with HIV were combined to create a set of dummy variables measuring whether the respondent: (a) knew no one with HIV at both waves (the omitted category in the analysis); (b) knew someone with HIV at wave 1 but not at wave 4; (c) knew someone with HIV at wave 4 but not at wave 1; or (d) knew someone with HIV at both waves.

\subsection{Sociodemographic Variables}

In models run separately by gender, race was included as a variable with dummies for coloureds and whites; blacks served as the omitted category. In models run separately by race, gender was included as a variable, coded 0 for females and 1 for males. We also included controls for respondent's age at wave 1 (coded in years) and educational attainment at wave 1 (coded as years of completed schooling).

\subsection{Analysis}

The sample was restricted to youth who had completed both the wave 1 and wave 4 surveys. Young people who had ever been married were excluded from the analysis, as married persons are likely to have different patterns of risk behaviors and different HIV risk perceptions than unmarried persons. We also excluded respondents with missing data or who answered "don't know" to any questions, as well as people whose race was unknown or was not black, coloured, or white. After these exclusions, the final sample for analysis was 2,348. (The sample for analysis limited to those who were sexually experienced by wave 4 was 1,837 ).

Multivariate analyses of change in HIV risk perceptions were performed using ordered logistic regression because the dependent variable is not continuous and therefore not appropriate for such methods as OLS regression. Ordered logistic regression is similar to logistic regression, except that it allows for multiple ordinal outcome levels rather than only two. We analyzed multivariate models of change in HIV risk perceptions separately for males and females and separately for blacks, coloureds and whites. Sample size restrictions, especially for whites, prevented us from performing analyses for groups jointly defined by race and gender (such as white males). Analyses were performed in Stata/SE 10.1, using the "svy" commands to adjust standard errors to account for the complex survey design. Probability weights were used to adjust for the oversampling of blacks and whites and for nonresponse of households and youth, so that the results are representative of metropolitan Cape Town.

\section{RESULTS}

Table 1 presents weighted frequency distributions for the change in HIV risk perceptions variable (i.e., wave 4 risk perceptions score - wave 1 risk perceptions score) by gender and by race. For both males and females, the modal score is 0 , with approximately $47 \%$ of males and females reporting no change in HIV risk perceptions over time. Crosstabulations (not shown) indicate that most males and females with scores of 0 reported no risk of HIV at both waves of the survey. Frequency distributions (not shown) indicate that, for both genders, the "no risk" response category is both the mode and the median for the HIV risk perceptions question that appeared on the wave 1 and wave 4 surveys.

The second most common score on the change in HIV risk perceptions variable for both genders is 1 , indicating an increase in risk perceptions from wave 1 to wave 4. Crosstabulations (not shown) reveal that males and females with scores of 1 usually reported no perceived risk of HIV at wave 1 and a small risk of HIV at wave 4 . However, for both males and females, small declines in risk perceptions over time (i.e., scores of -1 , indicating a move from one level of perceived risk to the level immediately below it) are almost as common. Thus, within each gender, increases and decreases in risk perceptions nearly offset each other.

The modal score for the change in HIV risk perceptions variable for all three racial groups (black, coloured and white) is 0 , indicating no change in risk perceptions over the four-year period. But the percentage of blacks (42\%) having no change in risk perceptions is smaller than the percentages for coloureds $(49 \%)$ and whites $(46 \%)$. Frequency distributions by race (not shown) for the HIV risk perceptions question that appeared on the wave 1 and wave 4 surveys indicate that, for blacks, both the mode and median at wave 1 is the "no risk" category (selected by $72 \%$ of blacks), while at wave 4 the mode is the "no risk" category (selected by $45 \%$ of blacks) and the median is the "small risk" category (selected by $32 \%$ of blacks). For coloureds, the "no risk" response category is the mode and the median at wave 1 (chosen by $57 \%$ of coloured respondents) and at wave 4 (chosen by $62 \%$ of coloured respondents). For whites, the "small risk" response category is the mode and median at wave 1 (selected by $46 \%$ of whites) while the "no risk" response category is the mode and the median at wave 4 (selected by $64 \%$ of whites). 
Table 1. Change in HIV risk perceptions (wave 4 minus wave 1), by gender and race

\begin{tabular}{llllll}
\hline & Male & Female & Black & Coloured & White \\
\hline-3 & 0.034 & 0.025 & 0.032 & 0.030 & 0.014 \\
-2 & 0.053 & 0.058 & 0.032 & 0.068 & 0.047 \\
-1 & 0.172 & 0.168 & 0.085 & 0.185 & 0.328 \\
0 & 0.466 & 0.465 & 0.419 & 0.488 & 0.463 \\
1 & 0.211 & 0.211 & 0.260 & 0.199 & 0.139 \\
2 & 0.039 & 0.045 & 0.101 & 0.020 & 0.006 \\
3 & 0.026 & 0.028 & 0.071 & 0.010 & 0.003 \\
\hline
\end{tabular}

Among youth who change their risk perceptions, blacks are most likely to increase from one level of risk perceptions to the next highest level (26\% of blacks), coloureds are about as likely to increase their risk perceptions by one level as they are to decrease their risk perceptions by one level (20 and 19\% of coloureds, respectively) and whites who change their risk perceptions are most likely to decrease them by one level (33\% of whites). Overall though, blacks are more likely to change their risk perceptions by increasing them $(43 \%$ of the black sample) while coloureds and whites are more likely to change their risk perceptions by decreasing them (28 and $39 \%$ of the coloured and white samples, respectively).

Descriptive statistics for the sample are presented by gender in Table $\mathbf{2}$ and by race in Table 3, along with $\mathrm{p}$ values from t-tests. We focus our discussion on the dependent variable, change in HIV risk perceptions, and on independent variables with significant $(\mathrm{p}<0.05)$ differences in means across groups. The results in Table 2 indicate that the mean change in HIV risk perceptions between waves 1 and 4 is small for each gender, slightly negative for males and slightly positive for females. The gender difference in means for this variable is not statistically significant, however and the size of the standard errors suggests that the mean change in risk perceptions for both males and females does not differ from zero. Females are less likely not to know someone with HIV at both waves but are more likely to know someone with HIV at both waves. A higher percentage of males $(54 \%)$ report using a condom at last sex than females $(39 \%)$, while the mean age at first sex is higher by nearly a year for females (17.2) than for males (16.4).

The results in Table 3 indicate that, on average, blacks increase their risk perceptions over time while coloureds and whites decrease theirs. Mean changes in risk perceptions are significantly different between blacks and coloureds and between blacks and whites but not between coloureds and whites. Most coloureds $(84 \%)$ and whites $(92 \%)$ but less than half of blacks $(46 \%)$ report not knowing someone with HIV at both waves. Taken together, the results for the various measures of knowing someone with HIV indicate that blacks are much more likely to know someone with HIV at one or both waves than either coloureds or whites, and coloureds are generally more likely than whites to know someone with HIV.

The results for the measures of sexual behaviors show that blacks are the least likely to be virgins at both waves $(8 \%$ of blacks versus $31 \%$ of coloureds and $36 \%$ of whites) and are the most likely to have had first sex before wave 1 ( $55 \%$ of blacks versus $31 \%$ of coloureds and $20 \%$ of whites). Among those who have had sex, a much higher percentage of blacks $(68 \%)$ than coloureds $(31 \%)$ and whites $(48 \%)$ report using a condom at last sex. Mean age at first sex among the sexually experienced is lower for blacks (16.0) than for either coloureds (17.2) or whites (18.1). In most instances, there are statistically significant differences in engaging in (or not engaging in) sexual risk behaviors between blacks and coloureds, between blacks and whites and between coloureds and whites.

Table 4 shows the results of ordered logistic regression analyses of change in HIV risk perceptions by gender. For both genders, coloureds and whites have significantly reduced their risk perceptions between waves 1 and 4 relative to blacks. Years of education also are associated with a reduction in risk perceptions for both genders. For males, knowing someone with HIV at wave 4 but not at wave 1 is associated with an increase in perceived risk, relative to not knowing someone with HIV at both waves; for females, knowing someone with HIV does not significantly alter risk perceptions (at $\mathrm{p}<$ 0.05 ). For males, experiencing first sex between waves 1 and 4 is associated with an increase in perceived risk, relative to those who have not yet had sex. For females, experiencing first sex between waves 1 and 4 or before wave 1 is associated with an increase in perceived risk relative to being a virgin at both waves.

Table 5 reports the results of ordered logistic regression analyses of change in HIV risk perceptions by race. Gender is significant only for blacks, with black males more likely to have lowered their risk perceptions relative to black females. (Frequency distributions, not shown, indicate an increase in risk perceptions for $48 \%$ of black females compared to $37 \%$ of black males and a decrease in risk perceptions for $13 \%$ of black females compared to $17 \%$ of black males.) Educational attainment is significant only for coloureds, for whom more schooling is associated with reduced risk perceptions. 
Table 2. Descriptive statistics, by gender

\begin{tabular}{|c|c|c|c|c|c|}
\hline & \multicolumn{2}{|l|}{ Male } & \multicolumn{2}{|l|}{ Female } & \multirow[b]{2}{*}{$\mathrm{p}$} \\
\hline & Mean & Std err & Mean & Std err & \\
\hline Change in HIV/AIDS risk perceptions between waves $1 \& 4$ & -0.013 & 0.045 & 0.024 & 0.037 & 0.484 \\
\hline Age (wave 1) & 17.401 & 0.080 & 17.464 & 0.081 & 0.577 \\
\hline Black & 0.294 & 0.016 & 0.291 & 0.014 & 0.858 \\
\hline Coloured & 0.605 & 0.018 & 0.612 & 0.017 & 0.740 \\
\hline White & 0.101 & 0.009 & 0.097 & 0.011 & 0.804 \\
\hline Education in wave 1 (years) & 9.082 & 0.073 & 9.407 & 0.069 & 0.000 \\
\hline Did not know someone with HIV at both waves $1 \& 4$ & 0.766 & 0.015 & 0.710 & 0.017 & 0.006 \\
\hline Knew someone with HIV at wave 1 but not wave 4 & 0.069 & 0.008 & 0.083 & 0.013 & 0.361 \\
\hline Knew someone with HIV at wave 4 but not wave 1 & 0.119 & 0.011 & 0.143 & 0.011 & 0.077 \\
\hline Knew someone with HIV at both waves $1 \& 4$ & 0.046 & 0.007 & 0.064 & 0.007 & 0.016 \\
\hline Virgin at both waves $1 \& 4$ (omitted) & 0.226 & 0.017 & 0.266 & 0.016 & 0.077 \\
\hline Experienced first sex between waves $1 \& 4$ & 0.392 & 0.018 & 0.371 & 0.015 & 0.345 \\
\hline Non-virgin at both waves $1 \& 4$ & 0.382 & 0.017 & 0.363 & 0.016 & 0.406 \\
\hline Used a condom as last sex (wave 4$)^{*}$ & 0.536 & 0.020 & 0.384 & 0.020 & 0.000 \\
\hline Age at first sex* & 16.378 & 0.091 & 17.225 & 0.068 & 0.000 \\
\hline
\end{tabular}

$\mathrm{N}=1,083$ (male), 1,265 (female)

$* \mathrm{~N}=858$ (male), 979 (female)

Table 3. Descriptive statistics, by race

\begin{tabular}{|c|c|c|c|c|c|c|c|c|c|}
\hline & \multicolumn{2}{|l|}{ Black } & \multicolumn{2}{|c|}{ Coloured } & \multicolumn{2}{|l|}{ White } & \multirow{2}{*}{$\begin{array}{l}\text { Black vs } \\
\text { coloured } \\
\mathrm{p}\end{array}$} & \multirow{2}{*}{$\begin{array}{l}\text { Black vs } \\
\text { white } \\
\text { p }\end{array}$} & \multirow{2}{*}{$\begin{array}{l}\text { Coloured } \\
\text { vs white } \\
\text { p }\end{array}$} \\
\hline & Mean & Std err & Mean & Std err & Mean & Std err & & & \\
\hline Change in HIV/AIDS risk perceptions & 0.428 & 0.046 & -0.145 & 0.043 & -0.303 & 0.089 & 0.000 & 0.000 & 0.109 \\
\hline Age (wave 1) & 17.651 & 0.070 & 17.399 & 0.081 & 17.017 & 0.223 & 0.018 & 0.007 & 0.109 \\
\hline Male & 0.464 & 0.014 & 0.459 & 0.015 & 0.471 & 0.042 & 0.798 & 0.873 & 0.781 \\
\hline Education at wave 1 (years) & 8.843 & 0.068 & 9.296 & 0.072 & 10.234 & 0.227 & 0.000 & 0.000 & 0.000 \\
\hline Did not know someone with HIV at both waves $1 \& 4$ & 0.458 & 0.021 & 0.839 & 0.014 & 0.915 & 0.023 & 0.000 & 0.000 & 0.005 \\
\hline Knew someone with HIV at wave 1 but not wave 4 & 0.083 & 0.010 & 0.082 & 0.013 & 0.023 & 0.010 & 0.974 & 0.000 & 0.000 \\
\hline Knew someone with HIV at wave 4 but not wave 1 & 0.307 & 0.018 & 0.060 & 0.008 & 0.058 & 0.020 & 0.000 & 0.000 & 0.947 \\
\hline Knew someone with HIV at both waves $1 \& 4$ & 0.151 & 0.014 & 0.018 & 0.004 & 0.004 & 0.004 & 0.000 & 0.000 & 0.011 \\
\hline Virgin at both waves $1 \& 4$ (omitted) & 0.076 & 0.009 & 0.312 & 0.018 & 0.358 & 0.045 & 0.000 & 0.000 & 0.346 \\
\hline Experienced first sex between waves $1 \& 4$ & 0.374 & 0.016 & 0.374 & 0.017 & 0.441 & 0.041 & 0.978 & 0.128 & 0.136 \\
\hline Non-virgin at both waves $1 \& 4$ & 0.551 & 0.015 & 0.314 & 0.017 & 0.201 & 0.034 & 0.000 & 0.000 & 0.003 \\
\hline Used a condom at last sex (wave 4$)^{*}$ & 0.676 & 0.015 & 0.305 & 0.021 & 0.480 & 0.061 & 0.000 & 0.004 & 0.003 \\
\hline Age at first sex* & 15.996 & 0.060 & 17.184 & 0.081 & 18.089 & 0.204 & 0.000 & 0.000 & 0.000 \\
\hline
\end{tabular}

$\mathrm{N}=1,055$ (black), 1,140 (coloured), 153 (white)

$* \mathrm{~N}=972$ (black), 775 (coloured), 88 (white)

Table 4. Ordered logistic regression of change in HIV/AIDS risk perceptions, by gender

\begin{tabular}{|c|c|c|c|c|c|c|}
\hline & \multicolumn{3}{|l|}{ Male } & \multicolumn{3}{|l|}{ Female } \\
\hline & Coeff & Std err & $\mathrm{p}$ & Coeff & Std err & $\mathrm{p}$ \\
\hline Age (wave 1) & 0.017 & 0.033 & 0.609 & 0.050 & 0.034 & 0.142 \\
\hline Black (omitted) & - & - & - & - & - & - \\
\hline Coloured & -0.527 & 0.166 & 0.002 & -1.164 & 0.154 & 0.000 \\
\hline White & -0.677 & 0.258 & 0.009 & -1.583 & 0.242 & 0.000 \\
\hline Education at wave 1 (years) & -0.085 & 0.037 & 0.021 & -0.093 & 0.037 & 0.014 \\
\hline $\begin{array}{l}\text { Did not know someone with HIV } \\
\text { at both waves } 1 \& 4 \text { (omitted) }\end{array}$ & - & - & - & - & - & - \\
\hline Knew someone with HIV at wave 1 but not wave 4 & 0.002 & 0.250 & 0.995 & -0.156 & 0.278 & 0.574 \\
\hline Knew someone with HIV at wave 4 but not wave 1 & 0.431 & 0.201 & 0.033 & 0.084 & 0.164 & 0.611 \\
\hline Knew someone with HIV at both waves $1 \& 4$ & -0.242 & 0.346 & 0.484 & -0.400 & 0.242 & 0.099 \\
\hline Virgin at both waves $1 \& 4$ (omitted) & - & - & - & - & $-\quad-2$ & - \\
\hline Experienced first sex between waves $1 \& 4$ & 0.375 & 0.165 & 0.024 & 0.608 & 0.128 & 0.000 \\
\hline Non-virgin at both waves $1 \& 4$ & 0.188 & 0.223 & 0.399 & 0.533 & 0.172 & 0.002 \\
\hline $\mathrm{N}$ & 1.083 & & & 1.265 & & \\
\hline $\mathrm{F}$ & 4.61 & & & 17.96 & & \\
\hline $\mathrm{P}$ & 0.000 & & & 0.000 & & \\
\hline
\end{tabular}


Ann M. Beutel and Kermyt G. Anderson / Journal of Social Sciences 9 (1): 1-10, 2013

Table 5. Ordered logistic regression of change in HIV/AIDS risk perceptions, by race

\begin{tabular}{|c|c|c|c|c|c|c|c|c|c|}
\hline & \multicolumn{3}{|c|}{ Black } & \multicolumn{3}{|c|}{ Coloured } & \multicolumn{3}{|c|}{ White } \\
\hline & Coeff & Std err & $\mathrm{p}$ & Coeff & Std err & $\mathrm{p}$ & Coeff & Std err & $\mathrm{p}$ \\
\hline Age (wave 1) & 0.026 & 0.033 & 0.424 & 0.040 & 0.031 & 0.202 & 0.216 & 0.266 & 0.418 \\
\hline Female (omitted) & - & - & - & - & - & - & - & - & - \\
\hline Male & -0.449 & 0.127 & 0.001 & 0.000 & 0.130 & 0.997 & 0.476 & 0.372 & 0.204 \\
\hline Education in wave 1 (years) & -0.037 & 0.036 & 0.299 & -0.122 & 0.036 & 0.001 & -0.251 & 0.275 & 0.364 \\
\hline $\begin{array}{l}\text { Did not know someone with HIV at both waves } \\
1 \& 4 \text { (omitted) }\end{array}$ & - & - & - & - & - & - & & & \\
\hline Knew someone with HIV at wave 1 but not wave 4 & 0.165 & 0.227 & 0.469 & -0.224 & 0.254 & 0.378 & -0.817 & 1.031 & 0.430 \\
\hline Knew someone with HIV at wave 4 but not wave 1 & 0.199 & 0.148 & 0.180 & 0.207 & 0.260 & 0.426 & 0.767 & 0.832 & 0.359 \\
\hline Knew someone with HIV at both waves $1 \& 4$ & -0.172 & 0.188 & 0.362 & -0.664 & 0.473 & 0.163 & -1.527 & 0.602 & 0.013 \\
\hline Virgin at both waves $1 \& 4$ (omitted) & - & - & - & - & - & - & - & - & - \\
\hline Experienced first sex between waves $1 \& 4$ & 0.420 & 0.199 & 0.037 & 0.589 & 0.140 & 0.000 & 0.209 & 0.370 & 0.573 \\
\hline Non-virgin at both waves $1 \& 4$ & 0.135 & 0.212 & 0.525 & 0.426 & 0.184 & 0.022 & 0.882 & 0.567 & 0.123 \\
\hline $\mathrm{N}$ & 1,055 & & & 1,140 & & & 153 & & \\
\hline $\mathrm{F}$ & 4.240 & & & 3.760 & & & 6.200 & & \\
\hline $\mathrm{P}$ & 0.000 & & & 0.001 & & & 0.000 & & \\
\hline
\end{tabular}

Table 6. Ordered logistic regression of change in HIV/AIDS risk perceptions among sexually experienced respondents, by gender

\begin{tabular}{|c|c|c|c|c|c|c|}
\hline \multirow[b]{2}{*}{ Sexually experienced by wave 4} & \multicolumn{3}{|c|}{ Male } & \multicolumn{3}{|c|}{ Female } \\
\hline & Coeff & Std err & $\mathrm{p}$ & Coeff & Std err & $\mathrm{p}$ \\
\hline Age (wave 1) & $\begin{array}{l}-0.014 \\
\end{array}$ & 0.031 & 0.650 & 0.063 & 0.031 & 0.044 \\
\hline Black (omitted) & - & - & - & - & - & - \\
\hline Coloured & -0.433 & 0.189 & 0.022 & -0.864 & 0.168 & 0.000 \\
\hline White & -0.601 & 0.321 & 0.062 & -1.382 & 0.292 & 0.000 \\
\hline Education at wave 1 (years) & -0.068 & 0.036 & 0.061 & -0.072 & 0.042 & 0.084 \\
\hline $\begin{array}{l}\text { Did not know someone with HIV } \\
\text { at both waves } 1 \& 4 \text { (omitted) }\end{array}$ & - & - & - & - & - & - \\
\hline Knew someone with HIV at wave 1 but not wave 4 & 0.274 & 0.285 & 0.338 & -0.150 & 0.302 & 0.619 \\
\hline Knew someone with HIV at wave 4 but not wave 1 & 0.292 & 0.220 & 0.185 & 0.055 & 0.159 & 0.730 \\
\hline Knew someone with HIV at both waves $1 \& 4$ & -0.395 & 0.315 & 0.211 & -0.349 & 0.240 & 0.147 \\
\hline Used a condom at last sex & 0.395 & 0.149 & 0.008 & 0.225 & 0.141 & 0.111 \\
\hline Age at first sex & 0.018 & 0.038 & 0.631 & -0.090 & 0.034 & 0.009 \\
\hline $\mathrm{N}$ & 858 & & & 979 & & \\
\hline $\mathrm{F}$ & 4.000 & & & 9.870 & & \\
\hline $\mathrm{P}$ & 0.000 & & & 0.000 & & \\
\hline
\end{tabular}

Table 7. Ordered logistic regression of change in HIV/AIDS risk perceptions among sexually experienced respondents, by race

\begin{tabular}{|c|c|c|c|c|c|c|c|c|c|}
\hline \multirow[b]{2}{*}{ Sexually experienced by wave 4} & \multicolumn{2}{|c|}{ Black } & \multirow[b]{2}{*}{$\mathrm{p}$} & \multicolumn{3}{|c|}{ Coloured } & \multicolumn{3}{|l|}{ White } \\
\hline & Coeff & Std err & & Coeff & Std err & $\mathrm{p}$ & Coeff & Std err & $\mathrm{p}$ \\
\hline Age (wave 1) & 0.017 & 0.035 & 0.633 & 0.026 & 0.030 & 0.389 & 0.311 & 0.275 & 0.262 \\
\hline Female (omitted) & - & - & - & - & - & - & - & - & - \\
\hline Male & -0.506 & 0.139 & 0.000 & -0.206 & 0.149 & 0.170 & 0.440 & 0.496 & 0.379 \\
\hline Education at wave 1 (years) & -0.050 & 0.036 & 0.168 & -0.103 & 0.042 & 0.016 & -0.270 & 0.301 & 0.373 \\
\hline $\begin{array}{l}\text { Did not know someone with HIV at both waves } \\
1 \& 4 \text { (omitted) }\end{array}$ & - & - & - & - & - & - & - & - & - \\
\hline Knew someone with HIV at wave 1 but not wave 4 & 0.229 & 0.247 & 0.354 & -0.111 & 0.294 & 0.706 & -0.673 & 3.578 & 0.851 \\
\hline Knew someone with HIV at wave 4 but not wave 1 & 0.210 & 0.152 & 0.168 & 0.049 & 0.261 & 0.851 & 0.531 & 0.768 & 0.492 \\
\hline Knew someone with HIV at both waves $1 \& 4$ & -0.157 & 0.182 & 0.391 & -0.914 & 0.442 & 0.041 & -2.200 & 0.669 & 0.002 \\
\hline Used a condom at last sex & 0.095 & 0.127 & 0.458 & 0.440 & 0.158 & 0.006 & 0.616 & 0.491 & 0.214 \\
\hline Age at first sex & -0.040 & 0.040 & 0.323 & -0.010 & 0.033 & 0.752 & -0.216 & 0.097 & 0.030 \\
\hline $\mathrm{N}$ & 972 & & & 775 & & & 88 & & \\
\hline $\mathrm{F}$ & 3.260 & & & 3.350 & & & 6.120 & & \\
\hline $\mathrm{P}$ & 0.002 & & & 0.002 & & & 0.000 & & \\
\hline
\end{tabular}


No measure of knowing someone with HIV is significant for either blacks or coloureds; among whites, knowing someone with HIV at both waves (relative to not knowing someone with HIV at both waves) is associated with a reduction in perceived risk. Relative to being a virgin at both waves, experiencing first sexual intercourse between waves 1 and 4 is associated with increased risk perceptions for both blacks and coloureds, while having had first sex before wave 1 is associated with increased risk perceptions only for coloureds. No measure of sexual experience is significant for whites.

Table 6 presents the results of ordered logistic regression analyses of change in HIV risk perceptions by gender for those who reported being sexually experienced by wave 4 (i.e., those who experienced first sex prior to wave 1 or between waves 1 and 4). Age at wave 1 is associated with an increase in risk perceptions only for females. Relative to being black, being coloured or white is associated with reduced risk perceptions for both males and females, although the effect of being white is only marginally significant $(p=0.06)$ for males. No variable for knowing someone with HIV is significant for males or females. Using a condom at last sex is associated with an increase in risk perceptions only for males, while later age at first sex is associated with a decrease in risk perceptions only for females.

Table 7 shows the results of ordered logistic regression analyses of change in HIV risk perceptions among sexually experienced respondents by race. Gender is significant only for blacks, with black males having reduced their risk perceptions relative to black females. Educational attainment is significant only for coloureds, for whom it is a predictor of lowered risk perceptions. Relative to respondents who do not know someone with HIV at both waves, both coloureds and whites who reported knowing someone with HIV at both waves have lowered their risk perceptions. No measure of knowing someone with HIV is significant for blacks. Condom use at last sex is significant only for coloureds, for whom it is associated with increased risk perceptions. Age at first sex is significant only for whites, for whom later age at first sex is associated with reduced risk perceptions.

\section{DISCUSSION}

Although a number of prior studies have examined the influence of HIV risk perceptions on sexual risk behaviors among young South Africans (Anderson et al.,
2007, Tenkorang et al., 2009; 2011), no prior study (to the best of our knowledge) has examined changes in HIV risk perceptions over time using a representative sample of South African youth. We examined change in HIV risk perceptions using data from wave 1 (2002) and wave 4 (2006) of the Cape Area Panel Study (CAPS), a longitudinal study of youth and their households in Cape Town, South Africa. We also examined whether the factors associated with change in HIV risk perceptions vary by gender and by race.

For each gender, nearly half of respondents reported no perceived risk of HIV infection at both waves and the percentage of respondents reporting increases in risk perceptions was nearly equal to the percentage of respondents with decreases in risk perceptions. As a result, there was essentially no overall change in the HIV risk perceptions of either males or females and no significant gender difference for the mean change in risk perceptions.

We found the mean changes in risk perceptions to be significantly different between blacks and coloureds and between blacks and whites. Overall, blacks increase their risk perceptions over time while whites and coloureds decrease theirs. Analyses also revealed a gender difference in change for blacks, with black females significantly more likely to have an increase in their HIV risk perceptions than black males. This gender difference for blacks also was found when analysis was restricted to those with sexual experience.

Drawing upon the risk reappraisal hypothesis, we predicted that engagement in sexual risk behaviors would be associated with an increase in HIV risk perceptions and that engagement in risk reduction behaviors would be associated with a decrease in HIV risk perceptions. We found mixed support for these predictions. Individuals who experienced first sex between wave 1 and wave 4 tend to increase their risk perceptions. This relationship was found for males, females, blacks and coloureds, but not for whites. Having first sex before wave 1 is associated with increases in risk perceptions for females and for coloureds but not for males, blacks or whites. In addition, we found that among sexually experienced youth, later age at first sex is associated with lower risk perceptions for females and for whites. Contrary to our prediction, condom use among sexually experienced youth is associated with increased risk perceptions for males and for coloureds. These results may reflect a measurement issue. Condom use is a potentially problematic variable for studies of HIV risk perceptions and behaviors because condom use may be transitory (i.e., condom use at last sex does not mean the 
respondent has used condoms consistently or will use one at next intercourse) but usually is measured on surveys in terms of condom use at first sex and/or at last sex. More in-depth measures of condom use are needed in order to fully assess the relationship between condom use and HIV risk perceptions.

Drawing upon experiential theory, we expected that personal exposure to HIV/AIDS, in the form of knowing someone who has HIV, would lead to an increase in HIV risk perceptions. This hypothesis was largely unsupported. Relative to respondents who do not know someone with HIV at both waves, knowing someone with HIV at wave 4 but not at wave 1 is associated with increased risk perceptions, but only for the full sample of males (i.e., including both virgins and the sexually experienced). The relationship between knowing someone with HIV at both waves and change in risk perceptions is significant and negative, that is, in the opposite of the predicted direction, for three groups: the full sample of whites and the sexually experienced samples of coloureds and whites. Perhaps knowing someone with HIV/AIDS removes some of the fear and stigma associated with the disease, leading to a reduction in HIV risk perceptions (Maughan-Brown, 2010, gives evidence that HIV stigmatization may not change following personal contact with someone who has HIV).

Finally, we predicted that the correlates of change in HIV risk perceptions would vary by gender and race. This seems to be the case, as no variable is a consistently significant predictor of change in HIV risk perceptions for both genders or across all racial groups. Future research should investigate whether aspects of the social context pertaining to gender (e.g., gender norms pertaining to sex, women's ability to negotiate condom use) and to race (e.g., racial differences in the meaning of sexual activity) influence the process by which individuals assess and potentially change their HIV risk perceptions (Fraser-Hurt et al., 2011). Aspects of the community context (e.g., the extent of poverty) also may be important for understanding the complex relationship between HIV risk perceptions and risk behaviors (Tenkorang et al., 2011).

Two important limitations of our study should be noted. First, because the number of respondents in certain race and gender groups (especially for white males and white females) is small, we were unable to conduct analyses for groups defined by both gender and race. Such analyses would enhance our understanding of HIV risk perceptions over time. Second, our sample is representative of Cape Town, which is located in the Western Cape, a province that has lower HIV prevalence rates than many other provinces in South
Africa (Shisana et al., 2009; Fraser-Hurt et al., 2011). Change in HIV risk perceptions may occur differently (to the extent it occurs at all) in provinces with higher HIV prevalence rates, such as KwaZulu-Natal (Shisana et al., 2009; Fraser-Hurt et al., 2011).

\section{CONCLUSION}

This study is the first to use a representative sample of South African youth to document changes over time in HIV risk perceptions. When examined by gender, there is little change in HIV risk perceptions on average for males or females. When examined by race, there are increases in HIV risk perceptions on average for blacks and decreases in HIV risk perceptions on average for coloureds and whites. A key contribution of our study is the finding that being sexually experienced and in particular having first sex is associated with increases in perceived risk. But certain findings, namely that condom use at last sex is associated with increases rather than decreases in risk perceptions for some groups and that knowing someone with HIV is associated with decreases in risk perceptions for some groups, raise important questions about the relationship between sexual risk behaviors and change in HIV risk perceptions. These questions should be addressed in future research on HIV risk perceptions in South Africa.

\section{ACKNOWLEDGEMENT}

The Cape Area Panel Study Waves 1-2-3 were collected between 2002 and 2005 by the University of Cape Town and the University of Michigan, with funding provided by The Eunice Kennedy Shriver National Institute of Child Health and Human Development (NICHD) and the Andrew W. Mellon Foundation. Wave 4 was collected in 2006 by the University of Cape Town, University of Michigan and Princeton University. Major funding for the fourth wave was provided by the National Institute on Aging through a grant to Princeton University, in addition to funding provided by NICHD through the University of Michigan.

\section{REFERENCES}

Aiken, L., M.A. Gerend, K.M. Jackson and K.W. Ranby, 2012. Subjective Risk and Health-Protective Behavior: Prevention and Early Detection. In: Handbook of Health Psychology, $2^{\text {nd }}$ Edn., Baum, A., T.A. Revenson and J. Singer (Eds.), Psychology Press, New York, ISBN-10: 080586461X, pp: 113-145. 
Anderson, K.G. and A.M. Beutel, 2007. HIV/AIDS prevention knowledge among youth in Cape Town, South Africa. J. Soc. Sci., 3: 143-150. DOI: 10.3844 jssp.2007.143.150

Anderson, K.G., A.M. Beutel and B. Maughan-Brown, 2007. HIV risk perceptions and first sexual intercourse among youth in Cape Town, South Africa. Int. Fam. Plan. Perspec., 33: 98-105.

Brewer, N.T., N.D. Weinstein, C.L. Cuite and J.E. Herrington, 2004. Risk perceptions and their relation to risk behavior. Ann. Behav. Med., 27: 125-130. DOI: $10.1207 / \mathrm{s} 15324796 \mathrm{abm} 2702 \_7$

Dinkelman, T., D. Lam and M. Leibbrandt, 2007. Household and community income, economic shocks and risky sexual behavior of young adults: Evidence from the Cape Area Panel Study 2002 and 2005. AIDS, 21: 49-56. DOI: 10.1097/01.aids.0000300535.05226.a9

Fraser-Hurt, N., K. Zuma, P. Njuho, F. Chikwava and E. Slaymaker et al., 2011. The HIV epidemic in South Africa: What do we know and how has it changed? HSRC Press, Cape Town.

Kenyon, C., A. Boulle, M. Badri and V. Asselman, 2010b. "I don't use a condom (with my regular partner) because I know that I'm faithful, but with everyone else I do": The cultural and socioeconomic determinants of sexual partner concurrency in young South Africans. SAHARA J., 7: 35-43. DOI: 10.1080/17290376.2010.9724967

Kenyon, C., S. Zondo and M. Badri, 2010a. Determinants of self-perceived HIV risk in young South Africans engaged in concurrent sexual relationship. Afr. J. Reprod. Health, 14: 171-181. PMID: 21495610

Kincaid, D.L. and W. Parker, 2008. National AIDS communication programmes, HIV prevention behaviour and HIV infections averted in South Africa, 2005. National Strategic Plan Information Resource for South Africa.

Kirby, D.B., B.A. Laris and L.A. Rolleri, 2007. Sex and HIV education programs: Their impact on sexual behaviors of young people throughout the world. J. Adolesc. Health, 40: 206-217. DOI: 10.1016/j.jadohealth.2006.11.143

Lam, D., C. Ardington, N. Branson, A. Case and M. Leibbrandt et al., 2008. The Cape Area Panel Study: A very short introduction to the integrated waves 12-3-4 (2002-2006) data. University of Cape Town, Cape Town.
Macintyre, K., N. Rutenberg, L. Brown and A. Karim, 2004. Understanding perceptions of HIV risk among adolescents in KwaZulu-Natal. AIDS Behav., 8: 237-250. DOI: 10.1023/B:AIBE.0000044072.71361.b3

Maughan-Brown, B., 2010. Stigma rises despite antiretroviral roll-out: A longitudinal analysis in South Africa. Soc. Sci. Med., 70: 368-374. DOI: 10.1016/j.socscimed.2009.09.041

Moore, S. and D. Rosenthal, 1991. Adolescent invulnerability and perceptions of AIDS risk. J. Adolesc. Res., 6: 164-180. DOI: 10.1177/074355489162002

Pettifor, A., K. O'Brien, C. MacPhail, W.C. Miller and H. Rees, 2009. Early coital debut and associated HIV risk factors among young women and men in South Africa. Int. Perspect. Sex. Reprod. Health, 35: 74-82. DOI: $10.1363 / 3508209$

Pettifor, A.E., et al., 2004. HIV and sexual behaviour among young South Africans: A national survey of 15-24 year olds. Reproductive Health Research Unit, University of the Witwatersrand, Johannesburg.

Shisana, O. and L.C. Simbayi, 2002. South African National HIV Prevalence, HIV Incidence, Behaviour and Communication Survey, 1st Edn., HSRC Press, Cape Town, ISBN-10: 0796920079, pp: 121.

Shisana, O., et al., 2009. South African National HIV Prevalence, Incidence, Behaviour and Communication Survey, 2008: A Turning Tide Among Teenagers? 1st Edn., H, Cape Town, ISBN10: 0796922918, pp: 98.

Shisana, O. et al., 2005. South African National HIV Prevalence, HIV Incidence, Behaviour and Communication Survey, 2005. 1st Edn., HSRC Press, Cape Town, ISBN-10: 0796921520, pp: 156.

Tenkorang, E.Y., E. Maticka-Tyndale and F. Rajulton, 2011. A multi-level analysis of risk perception, poverty and sexual risk-taking among young people in Cape Town, South Africa. Health Place, 17: 525535. DOI: 10.1016/j.healthplace.2010.12.009

Tenkorang, E.Y., F. Rajulton and E. Maticka-Tyndale, 2009. Perceived risks of HIV/AIDS and first sexual intercourse among youth in Cape Town, South Africa. AIDS Behav., 13: 234-245. DOI: 10.1007/s10461-008-9470-5 